\title{
SK2 channels are required for function and long-term survival of efferent synapses on mammalian outer hair cells
}

\author{
Vidya Murthy ${ }^{1}$, Stéphane F. Maison ${ }^{2,3}$, Julián Taranda ${ }^{1,4}$, Nadeem Haque ${ }^{5, \dagger}$, Chris T. \\ Bond $^{6}$, A. Belén Elgoyhen ${ }^{4}$, John P. Adelman ${ }^{6}$, M. Charles Liberman ${ }^{2,3}$, and Douglas $E$. \\ Vetter ${ }^{1, *}$ \\ 1Tufts Univ. School of Medicine, Dept. of Neuroscience \\ 2Massachusetts Eye and Ear Infirmary, Eaton-Peabody Laboratory \\ 3Harvard Medical School, Dept. of Otology and Laryngology \\ 4Instituto de Investigaciones en Ingeniería Genética y Biología Molecular (INGEBI), Consejo Nacional de \\ Investigaciones Científicas y Técnicas (CONICET)
}

5Univ. of Notre Dame

6Vollum Institute, Oregon Health Sciences University

\begin{abstract}
Cochlear hair cells use SK2 currents to shape responses to cholinergic efferent feedback from the brain. Using SK2 $2^{-/}$mice, we demonstrate that, in addition to their previously defined role in modulating hair cell membrane potentials, SK2 channels are necessary for long-term survival of olivocochlear fibers and synapses. Loss of the SK2 gene also results in loss of electrically driven olivocochlear effects in vivo, and down regulation of ryanodine receptors involved in calciuminduced calcium release, the main inducer of nAChR evoked SK2 activity. Generation of doublenull mice lacking both the $\alpha 10 \mathrm{nAChR}$ gene, loss of which results in hypertrophied olivocochlear terminals, and the SK2 gene, recapitulates the SK2 ${ }^{-/}$synaptic phenotype and gene expression, and also leads to down regulation of $\alpha 9 \mathrm{nAChR}$ gene expression. The data suggest a hierarchy of activity necessary to maintain early olivocochlear synapses at their targets, with SK2 serving an epistatic, upstream, role to the nAChRs.
\end{abstract}

\section{Keywords}

cochlea; small conductance potassium channels; nicotinic receptors; synaptic degeneration; synaptogenesis

\footnotetext{
*corresponding author: Douglas Vetter, Dept. of Neuroscience, Tufts Univ. School of Medicine, 136 Harrison Ave., Boston, MA 02111, douglas.vetter@tufts.edu.

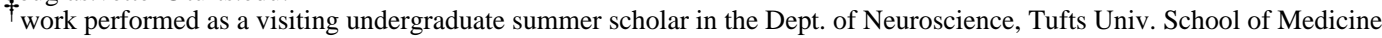

Publisher's Disclaimer: This is a PDF file of an unedited manuscript that has been accepted for publication. As a service to our customers we are providing this early version of the manuscript. The manuscript will undergo copyediting, typesetting, and review of the resulting proof before it is published in its final citable form. Please note that during the production process errors may be discovered which could affect the content, and all legal disclaimers that apply to the journal pertain.
} 


\section{Introduction}

Neuronal firing patterns are shaped by the characteristics of the after-hyperpolarization (AHP) following action potentials (Köhler et al., 1996; Hallworth et al., 2003; Bond et al., 2004). The AHP is composed of fast and slow components, mediated by the large conductance voltageand calcium-activated potassium (BK) channels, and the small conductance, slowly activating (SK) potassium channels, respectively. Control over the computational state of excitable cells can be exerted via activation of SK channels alone, as for example in hippocampal LTP, whereby adding or removing SK channels from the plasma membrane modulates EPSP strength (Lin et al., 2008).

The inner ear houses specialized epithelia containing hair cells, the sensory cells that transduce mechanical energy into the neural signals transmitted to the central nervous system. Cochlear hair cells can be functionally and spatially divided into inner and outer hair cells. Inner hair cells are responsible for conveying the detection of sound stimulation events to the brain, while outer hair cells are largely responsible for amplifying and modulating cochlear mechanics, and thus indirectly also impacting inner hair cell function. Unlike other cells responsible for sensory transduction outside the cochlea, outer hair cells receive direct efferent (descending) synaptic input thoughout life. Inner hair cells receive only a transient direct efferent innervation between 3 and 10 days after birth. This efferent system arises from the superior olivary region of the brain (Rasmussen, 1942), and is thus termed the olivocochlear (OC) system. The OC system is largely cholinergic, and the receptors mediating cholinergic neurotransmission in the cochlea are composed of $\alpha 9$ and $\alpha 10$ nAChR subunits (Elgoyhen et al., 1994, 2001; Vetter et al., 1999, 2007). These cells also express both BK (Hafidi et al., 2005) and SK type potassium channels (Dulon et al., 1998). While the apamin-sensitive SK channel family is composed of three family members (Köhler et al., 1996), only the SK2 form is expressed by mammalian hair cells (Dulon et al., 1998). While expression of the nAChRs establishes the cholinoceptive properties of hair cells, cholinergic OC effects stem from a combined nicotinic and SK2 response whereby an ACh-induced calcium flux ultimately activates SK2 channels, thus generating a hyperpolarizing response to efferent stimulation. The hair cell response therefore is a biphasic cellular response composed of a short latency depolarization followed by a significant hyperpolarization (Fuchs and Murrow, 1992; Blanchet et al., 1996; Dulon and Lenoir, 1996 ; Oliver et al., 2000). The functional coupling between SK2 channels and the nAChRs defines the postsynaptic unit by which efferent feedback onto hair cells exerts its action. The role, if any, of the early depolarizing response generated by the initial calcium entry through the ACh-activated channel is unknown. However, this synaptic property is shared by the inner ears of mammals, birds, fish, amphibia, and reptiles (Fuchs and Murrow, 1992a, b; Art et al., 1995; Blanchet et al., 1996; Dulon and Lenoir, 1996; Nenov et al., 1996; Dulon et al., 1998; Kros et al., 1998; Oliver et al., 2000; Dawkins et al., 2005; Holt et al., 2006), and therefore represents a basic mechanism of action underlying efferent feedback on hearing organs and perhaps even a conserved interdependent macromolecular structure important for hair cell cholinergic synapse assembly. In order to better understand the functional significance to hearing of generating a postsynaptic response of this type, as well as to investigate the consequences of the early calcium entry through the ACh-activated channels, we used mice carrying a null mutation for KCNN2, the gene for SK2.

\section{Results}

\section{Generation of the SK2/a10 compound null mouse line}

The generation of SK2 and $\alpha 10$ null mutants has already been described (Bond et al., 2004; Vetter et al., 2007). We have generated a compound-null mouse line carrying null mutations for both the SK2 and $\alpha 10$ genes (SK2 $2^{-/} / \alpha 10^{-/-}$mice) by crossing $\alpha 10^{-/-}$mice with SK2 ${ }^{+/-}$mice. Resultant double heterozygotes were identified and used to create the double nulls. As with 
SK2 ${ }^{-/-}$mice, double nulls are smaller than normal and exhibit ataxia and difficulties with righting reflex when placed on their back at young ages. While many double nulls die within the first week after birth, increased survival was obtained by early visual identification of double nulls followed by culling the litter of normal mice to decrease competition for nursing. Nonetheless, the vast majority of the double nulls die by 6 weeks of age. While the ataxia observed is similar to that reported for the $\mathrm{SK}^{-/-}$mice, reduced survival is unique to the doublenull line.

\section{Cochlear innervation}

SK2 ${ }^{-/-}$mice-Histological examination of the adult (2-4 month old) SK2 $2^{-/-}$cochlea showed no changes in overall structure and no loss of either inner or outer hair cells. However, synaptophysin immunostaining of the outer hair cell area revealed an age-related decline in number and size of OC terminals (Fig. 1). This synaptic terminal phenotype is opposite to the hypertrophy observed in $\alpha 9^{-/-}$(Fig. 1) and $\alpha 10^{-/-}$mice (Vetter et al., 1999,2007). At P18, OC terminals in SK2 ${ }^{-/}$mice showed small changes in size and number, and tunnel crossing fibers were beginning to show signs of degeneration. By 5-6 weeks, terminal number and size were clearly reduced (Fig. 2), and by 6 months, few or no efferent boutons remained on OHCs of the basal turn. In the apical turn, terminals sometimes persisted (data not shown). No synaptic terminal degeneration was observed in SK2 ${ }^{+/-}$mice. In the inner spiral bundle (ISB), few synaptophysin labeled terminals were organized beneath the inner hair cell (Fig. 3B), although there was an apparent increase in the number of fibers that left the main fiber tract and traversed toward the IHCs (Fig. 5B). The main longitudinal body of the ISB fiber tract, however, was not significantly different from wild type.

Immunostaining for tubulin (TuJ1) reveals OC fibers as they cross the tunnel of Corti (tunnel crossing fibers, Figs. 2, 3) to the outer hair cell region. Tunnel-crossing fibers of SK2 $2^{-/-}$mice at all ages examined were thin, with varicosities along their length (Fig. 3B, Supplementary Fig. 1). Such features were not observed in wild types and suggest ongoing degeneration. Counts of tunnel-crossing OC fibers in the mid-basal turn revealed loss in SK2 ${ }^{-/-}$mice beginning as early as P18-21, a time soon after the fibers initially cross the tunnel to encounter their targets (compare Fig. 3A,B; Fig. 4). Counts in wild type mice varied from 65 to 76 fibers/ $500 \mu \mathrm{m}$, without significant age-related change from 2 to 10 weeks (Fig. 4) and out to 6 months (data not shown). In SK2 ${ }^{-/}$mice, fiber counts were normal at 2 weeks of age, but fell with a roughly exponential time course to about $17.5 \%$ of the wild types by 10 weeks (Fig. 4). A twoway ANOVA (genotype $\times$ age) coupled with a Bonferroni post-hoc test for multiple comparisons t-test revealed statistically significant differences for all ages compared between genotype (3 wk, $\mathrm{p}<0.05 ; 4-10 w k, \mathrm{p}<0.001$ ).

TuJ1 immunostaining revealed abnormalities in the afferent innervation to OHCs as well. The long, spiraling dendrites of this system normally form compact fascicles in the outer spiral bundles (OSBs) underneath the OHCs. However, in the SK2 ${ }^{-/}$mice the OSBs were more loosely organized, with some fibers completely defasciculated from the bundle (Fig. 5).

Synaptophysin and TuJ immunostaining also revealed loss of OC terminals in the inner hair cell area of SK2 ${ }^{-/}$mice (Fig. 2, Fig. 3A, B, Fig. 5). The inner spiral bundle (ISB) normally consists of a compact spiral track of fibers giving rise to nests of terminals surrounding the base of IHCs (Fig. 3A, arrows, Fig. 5A). While the ISB was wider and more diffuse in $\mathrm{SK} 2^{-/-}$mice, the number of synaptophysin-positive terminals was dramatically reduced (Fig. 3B, 5B).

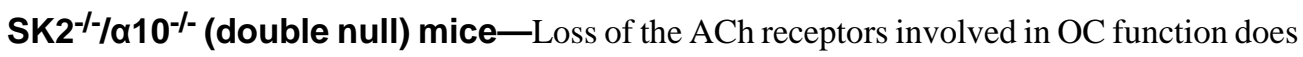
not result in loss of OC terminals or fibers (Vetter et al., 1999, 2007). This is unlike the case following loss of the functionally coupled SK2 potassium channel as described above. To better 
define the role of nAChRs and the SK2 channel in OC synapse development and/or survival, we generated SK2 ${ }^{-/} / \alpha 10^{-/-}$mice. This compound null leaves the $\alpha 9$ gene unaltered, and thus potentially retains $\mathrm{nAChR}$ activity mediated via homomeric $\alpha 9$ receptors, as previously described (see Fig. 2D of Vetter et al., 2007).

The compound SK2 $2^{-/} / \alpha 10^{-/-}$mice exhibited the same OC degeneration (Fig. 3B) observed in the SK2 ${ }^{-/}$mice (Fig. 3B), i.e. boutons in the $\mathrm{OHC}$ area were abnormally small by 3 weeks, and tunnel crossing fibers showed signs of degeneration as early as P18, with decreased fiber counts at all ages examined between 3 and 10 wks (Fig. 4). A two-way ANOVA of fiber counts in SK2 ${ }^{-/} / \alpha 10^{-/-}$mice versus wild type mice revealed statistically significant effects of genotype and age ( $3 \mathrm{wk}, \mathrm{p}<0.01,4-10 \mathrm{wk}, \mathrm{p}<0.001)$. Exponential curve fitting suggested an accelerated loss in the SK2 $2^{-/} / \alpha 10^{-/-}$compared to the SK2 $2^{-/-}$mice, with time constants of approximately 3 weeks and 5 weeks, respectively. Similar to SK2 $2^{-/-}$mice, the compound nulls did not exhibit loss of hair cells.

\section{Cochlear expression of NCAM in SK2-/- mice}

To better understand the mechanisms behind the degeneration of the OC fibers, western blots were produced to assess the expression level of Neural Cell Adhesion Molecule (NCAM), a cell adhesion molecule normally expressed by cochlear hair cells and OC fibers during the early postnatal synaptogenic phase of cochlear development. Pan-NCAM antibody recognized two well-described NCAM isoforms, migrating at $140 \mathrm{kDa}$ and $120 \mathrm{kDa}$. A third isoform, normally described as a $180 \mathrm{kDa}$ band was not observed in these cochlear lysates. Transfer was normal in this region of the gel as indicated by dye transfer of the molecular weight ladder, suggesting that these mice may not express the $180 \mathrm{kDa}$ isoform of NCAM, at least at appreciable levels, at these ages. Interestingly, NCAM protein expression of SK2 ${ }^{-/-}$mice at 6 weeks of age, a time at which active degeneration of OC fibers is still underway, is approximately 50\% higher than wild type (Fig. 10). The 15 week old SK2 $2^{-/-}$mice, in which OC fiber degeneration is essentially complete, demonstrated a significant down regulation of NCAM expression (50\% less than the six week old wild type levels) that was indistinguishable from age matched wild type mice (Fig. 10).

\section{In vivo cochlear function}

Neonatal elimination of the $\mathrm{OC}$ bundle can lead to auditory threshold elevation in the adult ear (Walsh et al., 1998). We therefore investigated baseline cochlear sensitivity in SK2 ${ }^{-1}$ - mice by examining auditory brainstem responses (ABRs), the summed activity of auditory neurons evoked by short tone pips, and distortion product otoacoustic emissions (DPOAEs), acoustic responses measured in the ear canal that are created and amplified by normal $\mathrm{OHC}$ function. No differences in threshold responses between adult (2 month old) SK2 $2^{-/-}$and wild type mice were detected at any of the frequencies tested, by either metric of cochlear function (Fig. 7A, B). Similar results were previously obtained in both $\alpha 9^{-/-}$and $\alpha 10^{-/-}$mice (Vetter et al., 1999, 2007).

To evaluate the role of the SK2 gene in OC function in the adult cochlea, we measured effects of OC electrical activation on DPOAE amplitudes in SK2 ${ }^{-/-}$ears using 8 week old mice. OC activation normally decreases the $\mathrm{OHC}$ contribution to cochlear amplification, thereby eliciting a fast suppression of DPOAE amplitudes after efferent activation onset (Fig. 8). The suppression is normally greatest for mid-frequency tones, mirroring the peak of OHC efferent terminal density in the middle of the cochlear spiral (Maison et al., 2003). In 8 week old $\mathrm{SK}^{-/-}$mice, an age when roughly $35 \%$ of OC innervation remains, efferent-evoked suppression of DPOAEs was never observed ( $\mathrm{n}=8$ ears tested at 6 different DPOAE-evoking frequencies). In most ears, the fast suppression was replaced by a small, slow-onset enhancement evoked by the shock train to the OC bundle, similar to previous reports on the 
$\alpha 9^{-/-}$and $\alpha 10^{-/-}$mice or in wild type mice treated with strychnine, a potent blocker of the $\alpha 9$ nAChR (Maison et al., 2007). In the group-mean data, these small effects were statistically significant at all frequencies (comparing pre-shock points to during shock points by t-test: $\mathrm{p}<0.001$ ). The small size of the OC-evoked enhancements in the SK2 ${ }^{-/}$ears (compared to that seen in $\alpha 10^{-/-}$mice) is consistent with the significant loss of OC fibers and terminals at 8 weeks (Figs. 1-4). Given the potential confounding variable of fiber degeneration on the results, 26 day old SK2 $2^{-/-}$mice, which still possess approximately $65 \%$ of the tunnel crossing fibers of wild types (Fig. 4) were examined. While these mice also showed no DP suppression, they did exhibit a stronger OC-evoked enhancement in response to efferent fiber activation (Fig. 8, triangles), likely resulting from the greater number of surviving OC fibers. While it would be best to use mice with no degenerative changes at all, mice younger than those used cannot reliably be used for this analysis. Expression of prestin (the molecular motor underlying OHC motility) matures at approximately 3 weeks of age (Abe et al., 2007), and distortion product generation continues to mature through the fourth postnatal week (Henley et al., 1990), thus confounding any results obtained at such ages.

\section{Cochlear gene expression}

qRT-PCR was performed on cochleae from adult wild type, SK2 ${ }^{-/-}$, and SK2 $2^{-/-} / \alpha 10^{-/-}$mice to examine expression levels of genes involved in synaptic transmission between OC terminals and their cochlear targets, as well as in general hair cell physiology. Equal amplification efficiency between all primers was verified (Supplemental Data Fig. 2). All results were first normalized against myosin VIIa expression and plotted with respect to wild type expression levels.

The genes assayed include Chrna 9 and Chrna10, encoding the $\alpha 9$ and $\alpha 10$ subunits comprising the nicotinic ACh receptor (nAChR) expressed by OHCs at the OC synaptic complex (Elgoyhen et al., 1994, 2001; Vetter et al., 1999, 2007), and the ryanodine receptor genes RyRl, $R y R 2$, and $R y R 3$, which encode proteins expressed in the subsynaptic cistern, an intracellular organelle likely responsible for amplifying calcium signals via calcium-induced calcium release (Lioudyno et al., 2004). Delta-delta CT analysis (Livak and Schmittgen, 2001) indicated no change in the steady-state mRNA levels of Chrna9, and small changes in Chrnal0 (up $33 \%$ ), and $R y R 3$ (down 16\%) mRNA in the SK2 $2^{-/-}$mice (Fig. 9). However, $R y R 1$ and $R y R 2$, expression levels decreased in the $\mathrm{SK}^{-/-}$mice at 7 weeks of age (74\% and 53\%, respectively, Fig. 8), coinciding with a time at which roughly $70 \%$ of the tunnel crossing fibers had degenerated (Fig. 4). While only moderate changes in RyR2, and RyR3 transcripts were detected in the $\mathrm{SK}^{-/-} / \alpha 10^{-/-}$mice (down regulated $22 \%$ and $28 \%$ respectively), Chrna 9 and $R y R 1$ expression level were more dramatically decreased (44\% and $60 \%$ respectively) in the double nulls at 5-6 weeks of age (Fig. 9). Because most double-null mice died by 6-8 weeks of age, qRT-PCR could not be carried out beyond this point.

Other ion channels also play a role in maturation of auditory function, including the BK channel (Rüttiger et al., 2004) and the L-type voltage activated calcium channel $\mathrm{Ca}_{\mathrm{V}} 1.3$ (Brandt et al., 2003; Michna et al., 2003; Nemzou et al., 2006). Therefore expression of Kcnmal and Kcnmb1, encoding the BK $\alpha$ and $\beta 1$ subunits respectively, and Cacnd1, encoding $\mathrm{Ca}_{\mathrm{V}} 1.3$, was also examined in the SK2 ${ }^{-/-}$mice to assess the maturational state of the auditory process (due to the low survival of double nulls and therefore less sample RNA, these genes were not investigated in the double null line). BK $\alpha$ was upregulated slightly (32\%), while BK $\beta 1$, involved in modulation of the BK channel gating properties and also its trafficking (Kim et al., 2007) was down regulated (37\%) while $\mathrm{Ca}_{\mathrm{V}} 1.3$ remained unchanged (Fig. 9). 


\section{Stabilization of the efferent postsynaptic complex}

The postsynaptic complex apposing olivocochlear terminals minimally contains the nACh receptor subunits and the SK2 channel. These proteins must be associated with cytoskeletal elements to anchor them at the synaptic pole. Given the combined observations of a persistent $\mathrm{nAChR}$ gene expression observed in the $\mathrm{SK} 2^{-/-}$mice, along with our inability to elicit electrically evoked OC activity, these data strongly suggest that an additional defect in $\mathrm{nAChR}$ targeting or assembly also exists in the SK2 $2^{--}$mice. While attempts at producing nAChR $\alpha 9$ subunit antibodies that meet high standards of specificity have not been successful, one may still assess to what extent the SK2 channel participates in stabilization of the postsynaptic complex, and thereby imply mechanisms to explain the loss of nAChR function, by examining the behavior of SK2 in the absence of one of the nAChR subunits. Loss of SK2 protein from the synaptic pole in the absence of nAChR subunit expression may indicate that SK2 and the nAChRs are linked together via adapter proteins and then further linked to an underlying cytomatrix. Thus, we examined the immunolocalization of SK2 in OHCs of a9-/- mice.

Immunostaining for SK2 in the $\alpha 9^{-/-}$mouse revealed precocious expression of SK2 in the OHCs (compare Fig. 10A and 10B). Additionally, at these early postnatal stages of olivocochlear fiber invasion, SK2 was not localized to the base of the OHCs, but rather decorated the lateral walls of the OHCs (Fig. 10B, C). However, with maturation, SK2 expression ceased along the basolateral surfaces of the hair cells, and was found only at the synaptic pole of the OHCs apposed to OC terminals (Fig. 10D).

\section{Discussion}

Expression of the SK2 channel and the nAChR $\alpha 10$ subunit ceases in inner hair cells concomitant with the loss of ACh-inducible currents (Elgoyhen et al., 1994, 2001; Katz et al., 2004), a rise in BK channel expression (Hafidi et al., 2005), and onset of adult-like hearing. Outer hair cells, however, express both nAChR subunits and the SK2 channel throughout life, and functional coupling is maintained between them (Oliver et al., 2000; Katz et al., 2004). At a cellular level, the initial consequence of nAChR activity in hair cells is depolarization (Fuchs and Murrow, 1992a, b) due to calcium influx via the nAChRs, followed by rapid calciuminduced calcium release that activates SK2-mediated hyperpolarization (Lioudyno et al., 2004). Normal function of the OC synapse on OHCs decreases sound-evoked cochlear vibrations (Russell and Murugasu, 1997), and elevates cochlear thresholds by decreasing the normal amplification of motion mediated by OHCs (Vetter et al., 1999). These OC effects are lost following genetic manipulations of the nAChR complex (Vetter et al., 1999, 2007) that eliminate ACh-induced calcium influx, and when release of calcium from intracellular stores is blocked by drugs acting on the ryanodine receptor (Russell and Murugasu, 1997; Lioudyno et al., 2004). Thus, the calcium-activated SK2 channel occupies a central position in these important cochlear functions.

Our data strongly suggest that hair cell responses induced and/or modulated by OC activation are necessary for the survival of OC innervation and that these responses must involve SK2mediated hyperpolarization. Interestingly, our data examining the youngest SK2 ${ }^{-/-}$mice also indicate that without SK2 expression, the nAChR does not attain functional status, at least at the "systems" level defined by our inability to elicit the classic OC-mediated decrease of distortion product amplitudes. While one may wish to examine the SK2 $2^{-/-}$mice without any hint of OC fiber degeneration (for example, the one week old mice), the youngest age examined here (P26) represents among the earliest ages that can possibly be used for this analysis given the maturation time frame of prestin expression that underlies the mechanism of distortion product generation. Loss of functional $\mathrm{nAChR}$ function in the $\mathrm{SK}^{-/-}$mice results in a similar lack of in vivo effects of OC activation compared with the $\alpha 9$ and $\alpha 10$ nulls, which also show replacement of the normally rapid suppression of DP amplitude following OC fiber activation 
by a slow OC-evoked enhancement. Such enhancements mirror that elicited during strychnine block of $\alpha 9 / \alpha 10$ function in wild type mice (Maison, et al., 2007a). Given that the enhancements decrease with age in the $\mathrm{SK}^{-/-}$mice, hence correlated with a decrease in OC innervation, the data suggest that whatever the mechanism of the $\mathrm{OC}$ enhancement, it does require an intact OC fiber innervation to occur. Electrophysiological measures of ACh-induced activity in $\mathrm{SK} 2^{-/-}$mice have also revealed a lack of response at the channel level (P. Fuchs, pers. comm.).

Given the dual observations of unchanged $\alpha 9$ gene transcript levels and yet loss of AChmediated function in the SK2 ${ }^{-/-}$mice, one could interpret the loss of physiological function of $\mathrm{SK}^{-/-}$mice simply as a defect in $\mathrm{nAChR}$ subunits assembling into the cholinergic receptor macromolecular complex. However, it is unclear what feedback mechanism may be in place to alter nAChR assembly in the face of loss of SK2 unless the entire nAChR/SK2 channel complex is assembled prior to targeting/insertion into the membrane, and additionally that SK2 were to act in a dominant manner important for transport and/or targeting of the entire protein complex. Because SK2 binds directly to $\alpha$-actinin 2 in heart muscle (Lu et al., 2007), and given that some neurotransmitter receptors are similarly bound and targeted to the membrane by cytoskeletal elements (Cabello et al., 2007), it may be that SK2 represents a component around which the remainder of the postsynaptic SK2/nAChR multiprotein complex coalesces via linker proteins into a functional core complex ready for membrane insertion, but that is stabilized to the cytomatrix via components unique to the SK2 channel. Such scenarios are not unprecedented. For example, numerous proteins involved in synaptic vesicle dynamics make up a large portion of presynaptic active zones and are assembled into Piccolo-Bassoon transport vesicles (PTVs) prior to membrane insertion (Shapira et al., 2003), demonstrating a lack of apparent upper limits on the size of such macromolecular assemblies.

In support of such a scenario, our data demonstrate the release of SK2 from the synaptic pole of OHCs in the absence of $\alpha 9 \mathrm{nAChR}$ subunits during early postnatal stages of synaptic refinement in the inner ear, but ultimately that SK2 is localized normally to the synaptic pole in the absence of nAChR expression yet, in the absence of SK2 expression, no ACh-inducible activity occurs. Together, the findings using the $\mathrm{SK} 2^{-/-}$and $\mathrm{nAChR} \alpha 9^{-/-}$mice suggest that one plausible explanation of the loss of ACh-mediated currents in the SK2 ${ }^{-/-}$mice is that SK2 stabilizes and anchors the hair cell nAChRs, but that the nAChRs do not play an appreciable role in stabilizing and/or anchoring SK2 (since SK2 is still found apposed to mature OC terminals in the $\alpha 9^{-/-}$mice despite early mis-localization at a time prior to OC synaptic innervation). This would imply that the nAChR/SK2 postsynaptic complex is anchored via components native to the SK2 protein. Final resolution of whether this scenario is true awaits good nAChR antibodies, a general problem plaguing the field (Moser et al., 2007).

The postnatal degeneration of OC terminals in SK2 ${ }^{-/-}$mice contrasts with the developmental hypertrophy and postnatal stability of OC terminals found in both $\alpha 9$ and $\alpha 10$ nulls (Vetter et al., 1999, 2007). While far from a complete mechanistic answer to reasons for the degeneration observed, our data indicate that the hair cells actually seem to be trying to hold onto the degenerating OC terminals, insofar as one may interpret the upregulation of the cell adhesion molecule NCAM during the degenerative process. NCAM is normally involved in target recognition and stabilization of the OC fibers at their target as OC synapses are generated (Whitlon and Rutishauser, 1990; Whitlon et al., 1999). Thus, loss of OHC adhesion seems not to be a mechanism by which these fibers are shed from OHCs in the SK2 ${ }^{-/}$mice. Further analysis will be required to better understand the mechanism behind the fiber degeneration observed in $\mathrm{SK}^{-/-}$mice.

Finally, we addressed the question of whether the SK2 or $\alpha 10$ (if either) gene dominates OC synapse formation and survival at OHCs by generating and studying a compound-null mouse line lacking both SK2 and $\alpha 10$ genes. Since the compound SK2-// $/ 10^{-/-}$mice showed synaptic 
degeneration similar to that following ablation of SK2 alone, it can be surmised that minimally presence of the SK2 channel, if not actually its activity, plays a dominant role in shaping, or even driving the initial development of OC fiber- hair cell contacts, and appears key to the survival of these synapses. If our proposed scenario of $\mathrm{SK} 2 / \mathrm{nAChR}$ subunit protein interactions is correct as described above, this event may not be surprising, as with the loss of SK2 would by default also come the loss of membrane insertion/stabilization of nAChRs, automatically nullifying the possibility that the nAChR synaptic phenotype can express itself. The normal efferent innervation observed in SK2 heterozygotes and overexpressers (Maison et al, 2007b) suggests that a minimal SK2 response (the presumptive state of the heterozygotes) is sufficient for maintenance of normal OC synapses, and overexpression of the gene has no deleterious effects on synaptic structure. Therefore, SK2 channel activity is clearly upstream of, and epistatic to, the role of nAChRs in synapse maintenance, since the previously observed synaptic hypertrophy of the $\alpha 10^{-/-}$mice is masked (or altered) by the phenotype expressed following ablation of the SK2 gene. The fact that OC fiber degeneration occurs only when the SK2 gene is ablated further suggests a recessive epistatic state.

Taken together, our gene and protein expression data, coupled with the systems level functional data presented, indicate that expression of SK2 establishes (whether it be via activity or structure) an environment upon which $n A C h R$ subunit gene expression can then exert a further effect (not necessarily limited to nAChR expression alone) to facilitate OC synaptic maintenance programs. Such a state demonstrates for the first time a distinct, two-step process in OC nicotinic synaptogenesis, and clearly demonstrates a previously unknown requirement for SK2 expression in $\mathrm{nAChR}$ expression and function. It is important to recognize, however, that this data do not necessarily predict a direct protein:protein interaction between SK2 and $\alpha 9 / 10$, but rather simply point to an interaction along a signaling cascade, an intersection of signaling networks, or, more likely, an indirect interaction via linker proteins during macromolecular assembly.

Control over the conductance of SK channels represents a mechanism by which firing reliability and temporal precision can be controlled (Hallworth et al., 2003), thereby modulating signal integration. Such a control mechanism can have profound implications for auditory system function, given the spontaneous activity of hair cells during development, and the importance of temporal characteristics of auditory activity along the central neural pathways. By inducing SK2 activity, the efferent system modulates these discharge patterns, and may thereby also shape central auditory development. Expression of SK2 seems to ensure proper expression and function of the nAChRs as well, further demonstrating the key role played by SK 2 in cochlear efferent function, and defining the OC postsynaptic complex as an indivisible nAChR/SK2 macromolecular entity.

\section{Materials and Methods}

\section{Null mutant mice}

Generation and initial characterization of both the $\mathrm{SK}^{-/-}$and $\alpha 10^{-/-}$mice have been previously described (Bond et al., 2004); (Vetter et al., 2007). The SK2 ${ }^{-/-}$strain background is $\mathrm{C} 57 \mathrm{Bl} / 6 \mathrm{~J}$, and the $\alpha 10^{-/-}$strain background is B6.CAST-Cdh23 $3^{\mathrm{AHL}+} / \mathrm{Kjn}$ (stock \#2756). The B6.CAST line is a congenic line in which one of the prominent age-related hearing loss loci of the C57B1/ $6 \mathrm{~J}$ was replaced with the Cast.Ei locus. Other than this manipulation, the strains are identical. Compound-null mice carrying deletions for both SK2 and $\alpha 10$ genes $\left(\mathrm{SK} 2^{--_{-}} / \alpha 10^{-/-}\right.$) were generated by first breeding $\alpha 10^{-/-}$to SK2 ${ }^{+/-}$. Following genotyping to identify double heterozygotes, breeding was continued to generate double nulls by first generating a population of mice that were $\mathrm{SK}^{+/-}$on an $\alpha 10^{-/-}$background. Upon production of the SK2 $2^{+-/} / \alpha 10^{-/-}$line, pairs from this line were used to establish the SK2 $2^{-/ /} / \alpha 10^{-/-}$line. Controls were generated from 
the appropriate crosses of SK2 and $\alpha 10$ colonies to further generate the $\mathrm{SK} 2^{+/+} / \alpha 10^{+/+}$and $\mathrm{SK} 2^{-/-} / \alpha 10^{+/-}$mice.

\section{Immunostaining}

Cochleae were exposed, perfused through the round and oval windows with $4 \%$ paraformaldehyde in $0.1 \mathrm{M}$ sodium phosphate buffer at room temperature, isolated, and postfixed in the same fixative for one hour. Following post-fixation, the cochleae were decalcified (8\% EDTA in PBS) overnight at room temperature, or two to three days at $4^{\circ} \mathrm{C}$ on a rotator. Cochleae were subsequently stripped of the bony outer capsule, and individual turns of the cochlea were hand cut for whole-mount processing. Immunostaining of the efferent terminals was performed using a mouse anti-synaptophysin antibody (Millipore, Billerica, MA, MAB5258). Immunostaining of efferent fibers crossing the tunnel of Corti was performed with antibodies to SNAP25 (Sigma, St. Louis, MO; cat. \# S9684) and processed with biotinylated secondaries, $\mathrm{ABC}$ reagent (Vector Labs, Burlingame, $\mathrm{CA}$ ), and diaminobenzidine (DAB) for standard light microscopy, or TuJ-1 (class III $\beta$-tubulin, Neuromics, Northfield, MN; cat. \# MO15013) and processed with Oregon Green labeled secondary antibodies (Molecular Probes/ InVitrogen) for confocal microscopy. Tissue for confocal observation was mounted onto slides and coverslipped with SlowFade Gold (Molecular Probes/InVitrogen, Carlsbad, CA).

Tunnel-crossing fibers were counted in both DAB- or fluorescence-reacted portions of the midbasal turn. Fibers were counted in three randomly selected fields with a $40 \times$ objective and expressed as fibers per $500 \mu \mathrm{m}$. Statistical analysis was performed as a two way ANOVA (genotype $\times$ age) in Prism (version $4.0 b$ ).

Immunostaining for SK2 was similar to processing for whole mount cochlear sections through the decalcification step, after which, the cochleas were cryoprotected in 30\% sucrose/ $0.9 \%$

$\mathrm{NaCl}$ overnight at $4{ }^{\circ} \mathrm{C}$, and subsequently embedded in a peel away mold in OCT. Cryosectioning was performed on a Leica cryostat, and sections were directly mounted onto Superfrost Plus slides (Fisher), dried on a slid warmer at $35^{\circ} \mathrm{C}$, and then stored until use in a slide box at $-30^{\circ} \mathrm{C}$. Anti-SK2 antibody (Alomone Labs) was used at a final concentration of 1:1000.

\section{Quantitative RT-PCR}

Primers for genes of interest were purchased from Qiagen (QuantiTect PCR primer sets, Qiagen, Inc., Valencia, CA). Cochleae were harvested from adult (6-8 week old) mice composed of mixed sexes. During harvest, and prior to freezing, all cerebellum tissue was removed from the temporal bone. Cochleae were immediately frozen by immersion in liquid nitrogen and stored in a liquid nitrogen dewar. Sample processing was performed using 6 cochlea for each biological PCR replicate as follows: 1) cochleae were first weighed to assess the volume of Trizol (In Vitrogen, Carlsbad, CA) needed in subsequent steps; 2) transferred to the appropriate volume of Trizol and homogenized using disposable plastic generators (cat\# 1426126, Fisher Scientific, Waltham, MA) and a hand held polytron; and 3) RNA was prepared according to the manufacturers instructions, with two minor modifications. A first spin was performed at $2500 \times \mathrm{g}$ to sediment debris, and the supernatant was transferred to a fresh tube. For precipitation of the RNA, $0.8 \mathrm{M}$ sodium citrate, $1.2 \mathrm{M}$ sodium chloride was used in addition to the isopropanol step in the manufacturer's instructions. RNA concentration was assessed using a NanoDrop system, and integrity was assessed via analysis of electropherograms generated on an Agilent Technologies Bioanalyzer labchip (RNA 6000, Nano Assay mode).

Quantitative reverse transcription-PCR (qRT-PCR) analysis was performed using a one step RT-PCR procedure employing the QuantiTect SYBR Green RT-PCR kit (Qiagen, Inc.), HotStarTaq DNA polymerase (Qiagen, Inc.), and the QuantiTect primers of choice following 
manufacturer's recommendations. Triplicate reactions (i.e. technical replicates) using pooled cochleae of 3 mice were performed at least twice (the second and any subsequent replications with a new pool of 3 mice, i.e. biological replicates) for each primer set as separate reactions. Cycle-by-cycle and dissociation (melt curves) fluorescence data were collected as a SYBR Green fluorescence assay. PCR reactions were performed on a Stratagene MX4000 instrument (Stratagene, Inc., La Jolla, California). Analysis of relative fold change in gene expression was calculated via the $\Delta \Delta \mathrm{C}_{\mathrm{T}}$ method (Livak and Schmittgen, 2001) using myosin VIIa as a normalizing standard. Amplification efficiency of primers was initially monitored prior to performing the experiment to ensure equality between primer sets (see Supplemental Data Fig. 2). Because of limited sample, a post-hoc statistical power score was also generated to ensure sufficient power (large enough sample size) of the study for interpretation of results. A power score greater than $80 \%$ was used as threshold for sufficient power, and if met, a greater number of samples was deemed unnecessary.

\section{Western blotting for protein expression levels}

Cochlear lysates were produced using the entire cochlear capsule. Cerebellar pieces, when present within the bounds of the semi-circular canals, were manually extracted prior to homogenization. Cochleae were pooled from at least three mice for each lysate. As each cochlear capsule was dissected free of the temporal bone, it was immersed in $1 \mathrm{ml}$ of ice cold Pierce T-PER Tissue Extraction reagent supplemented with protease inhibitor with EDTA (Pierce), and manually ground in a Kontes Duvall \#21 ground glass homogenizer. The lysate was then transferred to an eppendorf tube and centrifuged at $14 \mathrm{~K} \mathrm{rpm}$ for 20 minutes to sediment debris. The supernatant was recovered and used to determine protein concentration using a Pierce micro-BCA protein estimation kit. Lysate was then aliquoted and stored at $-35^{\circ}$ C until use.

Triplicate western (immuno-) blots, minimally using two different lysates per genotype pool (biological replicates), were carried out using standard SDS-PAGE procedures to determine expression levels. Gels were wet transferred to PVDF membrane (Bio-Rad) using wet transfer techniques. Blots were incubated at RT for 1 hour in 5\% non-fat milk, followed by an overnight incubation at $4^{\circ} \mathrm{C}$ in primary antibody (mouse anti-NCAM, BD Bioscience (clone NCAM13), $1: 1000)$. Washes were performed using PBS-Tween 20 for 30 minutes, followed by incubation in species appropriate peroxidase labeled secondary $(1: 2000)$. Bands were visualized using Pierce DuraWest ECL on a Kodak ImageStation 440. Quantification of all bands was performed by generating a densitometric ratio (Un-Scan-It gel, Silk Scientific) to GAPDH, used as a loading control. Six week old SK2 ${ }^{+/+}$values were then set to $100 \%$, and all values of other bands were normalized to this condition.

\section{Cochlear physiology}

Cochlear Sensitivity-All physiological experiments were conducted in a temperaturecontrolled, soundproof chamber maintained at $\sim 32^{\circ} \mathrm{C}$. Acoustic stimuli were presented via a custom acoustic assembly consisting of two electrostatic drivers (Tucker Davis Technologies, EC-1) to generate acoustic stimuli and a Knowles miniature microphone (EK3103) to record ear-canal sound pressure. Stimuli were generated, and responses measured, with locked digital I-O boards at 4- $\mu$ sec sampling (National Instruments, AO-6052E). Mice were anesthetized with xylazine (20 mg/kg i.p.) and ketamine (100 mg/kg i.p.). To measure auditory brainstem responses (ABRs), needle electrodes were inserted at vertex and pinna, with a ground near the tail. ABR potentials were evoked with $5-\mathrm{ms}$ tone pips delivered at $35 / \mathrm{sec}$. The response was amplified $(10,000 \mathrm{X})$, filtered $(100 \mathrm{~Hz}-3 \mathrm{kHz})$, and averaged with an A-D board in a LabVIEW-driven data-acquisition system. Sound level was raised in $5 \mathrm{~dB}$ steps from $10 \mathrm{~dB}$ below threshold up to $80 \mathrm{~dB}$ SPL. Upon visual inspection of stacked waveforms, 'threshold' was defined as the lowest SPL level at which any wave could be detected. To measure distortion 
product otoacoustic emissions (DPOAEs), two primary tones $\mathrm{f}_{1}$ and $\mathrm{f}_{2}$ ( with $\mathrm{f}_{2} / \mathrm{f}_{1}=1.2$ and $\mathrm{f}_{2}$ level $10 \mathrm{~dB}<\mathrm{f}_{1}$ level) were presented continuously to the ear canal. Ear-canal sound pressure was amplified and digitally sampled at $20 \mu$ s (National Instruments, A-2000). FFTs were computed and averaged over 5 consecutive waveform traces, and $2 \mathrm{f}_{1}-\mathrm{f}_{2}$ DPOAE amplitude and surrounding noise floor were extracted, a procedure requiring $\sim 4$ seconds of data acquisition and processing time.

Olivocochlear Assay-Adult (2 months old) and juvenile (P26) mice were anesthetized with urethane (1.20 g/kg i.p.) and xylazine ( $20 \mathrm{mg} / \mathrm{kg}$ i.p.). A posterior craniotomy and partial cerebellar aspiration were performed to expose the floor of the IV ${ }^{\text {th }}$ ventricle. To stimulate the OC bundle, shocks (monophasic pulses of $150 \mu$ s duration presented at 200/sec) were applied through fine silver wires $(0.4 \mathrm{~mm}$ spacing) placed along the midline, spanning the OC decussation. Shock threshold for facial twitches was determined, muscle paralysis induced with $\alpha$-d-tubocurarine $(1.25 \mathrm{mg} / \mathrm{kg}$ i.p.), and the animal connected to a respirator via a tracheal cannula. Shock levels were raised to $6 \mathrm{~dB}$ above twitch threshold. During the $\mathrm{OC}$ suppression assay, $\mathrm{f}_{2}$ level was typically set to produce a DPOAE $\sim 10-15 \mathrm{~dB}>$ noise floor. To measure OC effects, repeated measures of baseline DPOAE amplitude were first obtained ( $n=12)$, followed by a series of 17 continuous periods in which DPOAE amplitudes were measured with simultaneous shocks to the OC bundle. In some experiments, DPOAE measures and CAP measures were interleaved before during and after the OC shock train.

\section{Supplementary Material}

Refer to Web version on PubMed Central for supplementary material.

\section{Acknowledgements}

This work was supported by: NIH R01 DC006258 (DEV), R01 DC0188 (MCL), P30 DC 05209 (MCL), and The

Tufts Center for Neuroscience Research Imaging Core and Genomics Core P30 NS047243.

\section{References}

Abe T, Kakehata S, Kitani R, Maruya S, Navaratnam D, Santos-Sacchi J, Shinkawa H. Developmental Expression of the Outer Hair Cell Motor Prestin in the Mouse. J Membr Biol 2007;215:49-56. [PubMed: 17415610]

Art J, Wu Y, Fettiplace R. The calcium-activated potassium channels of turtle hair cells. J Gen Physiol 1995;105:49-72. [PubMed: 7730789]

Blanchet C, Eróstegui C, Sugasawa M, Dulon D. Acetylcholine-induced potassium current of guinea pig outer hair cells: its dependence on a calcium influx through nicotinic-like receptors. J Neurosci 1996;16:2574-2584. [PubMed: 8786433]

Bond C, Herson P, Strassmaier T, Hammond R, Stackman R, Maylie J, Adelman J. Small conductance $\mathrm{Ca} 2+$-activated $\mathrm{K}+$ channel knock-out mice reveal the identity of calcium-dependent afterhyperpolarization currents. J Neurosci 2004;24:5301-5306. [PubMed: 15190101]

Brandt A, Striessnig J, Moser T. CaV1.3 channels are essential for development and presynaptic activity of cochlear inner hair cells. J Neurosci 2003;23:10832-10840. [PubMed: 14645476]

Cabello N, Remelli R, Canela L, Soriguera A, Mallol J, Canela EI, Robbins MJ, Lluis C, Franco R, McIlhinney RA, Ciruela F. Actin-binding protein alpha-actinin-1 interacts with the metabotropic glutamate receptor type $5 \mathrm{~b}$ and modulates the cell surface expression and function of the receptor. $\mathrm{J}$ Biol Chem 2007;282:12143-12153. [PubMed: 17311919]

Dawkins R, Keller S, Sewell W. Pharmacology of acetylcholine-mediated cell signaling in the lateral line organ following efferent stimulation. J Neurophysiol 2005;93:2541-2551. [PubMed: 15615825]

Dulon D, Lenoir M. Cholinergic responses in developing outer hair cells of the rat cochlea. Eur J Neurosci 1996;8:1945-1952. [PubMed: 8921285] 
Dulon D, Luo L, Zhang C, Ryan A. Expression of small-conductance calcium-activated potassium channels (SK) in outer hair cells of the rat cochlea. Eur J Neurosci 1998;10:907-915. [PubMed: 9753158]

Elgoyhen A, Vetter D, Katz E, Rothlin C, Heinemann S, Boulter J. alpha10: a determinant of nicotinic cholinergic receptor function in mammalian vestibular and cochlear mechanosensory hair cells. Proc Natl Acad Sci USA 2001;98:3501-3506. [PubMed: 11248107]

Elgoyhen AB, Johnson DS, Boulter J, Vetter DE, Heinemann S. Alpha 9: an acetylcholine receptor with novel pharmacological properties expressed in rat cochlear hair cells. Cell 1994;79:705-715. [PubMed: 7954834]

Fuchs P, Murrow B. A novel cholinergic receptor mediates inhibition of chick cochlear hair cells. Proc Biol Sci 1992;248:35-40. [PubMed: 1355909]

Fuchs P, Murrow B. Cholinergic inhibition of short (outer) hair cells of the chick's cochlea. J Neurosci 1992;12:800-809. [PubMed: 1545240]

Hafidi A, Beurg M, Dulon D. Localization and developmental expression of BK channels in mammalian cochlear hair cells. Neuroscience 2005;130:475-484. [PubMed: 15664704]

Hallworth N, Wilson C, Bevan M. Apamin-sensitive small conductance calcium-activated potassium channels, through their selective coupling to voltage-gated calcium channels, are critical determinants of the precision, pace, and pattern of action potential generation in rat subthalamic nucleus neurons in vitro. J Neurosci 2003;23:7525-7542. [PubMed: 12930791]

Henley CM 3rd, Owings MH, Stagner BB, Martin GK, Lonsbury-Martin BL. Postnatal development of 2f1-f2 otoacoustic emissions in pigmented rat. Hear Res 1990;43:141-148. [PubMed: 2312410]

Holt J, Lysakowski A, Goldberg J. Mechanisms of efferent-mediated responses in the turtle posterior crista. J Neurosci 2006;26:13180-13193. [PubMed: 17182768]

Katz E, Elgoyhen A, Gómez-Casati M, Knipper M, Vetter D, Fuchs P, Glowatzki E. Developmental regulation of nicotinic synapses on cochlear inner hair cells. J Neurosci 2004;24:7814-7820. [PubMed: 15356192]

Kim EY, Zou S, Ridgway LD, Dryer SE. Beta1-subunits increase surface expression of a largeconductance Ca2+-activated K+ channel isoform. J Neurophysiol 2007;97:3508-3516. [PubMed: 17329633]

Köhler M, Hirschberg B, Bond C, Kinzie J, Marrion N, Maylie J, Adelman J. Small-conductance, calcium-activated potassium channels from mammalian brain. Science 1996;273:1709-1714. [PubMed: 8781233]

Kros C, Ruppersberg J, Rüsch A. Expression of a potassium current in inner hair cells during development of hearing in mice. Nature 1998;394:281-284. [PubMed: 9685158]

Lin MT, Lujan R, Watanabe M, Adelman JP, Maylie J. SK2 channel plasticity contributes to LTP at Schaffer collateral-CA1 synapses. Nat Neurosci 2008;11:170-177. [PubMed: 18204442]

Lioudyno M, Hiel H, Kong J, Katz E, Waldman E, Parameshwaran-Iyer S, Glowatzki E, Fuchs P. A "synaptoplasmic cistern" mediates rapid inhibition of cochlear hair cells. J Neurosci 2004;24:11160_ 11164. [PubMed: 15590932]

Livak K, Schmittgen T. Analysis of relative gene expression data using real-time quantitative PCR and the 2(-Delta Delta C(T)) Method. Methods 2001;25:402-408. [PubMed: 11846609]

Lu L, Zhang Q, Timofeyev V, Zhang Z, Young JN, Shin HS, Knowlton AA, Chiamvimonvat N. Molecular coupling of a Ca2+-activated $\mathrm{K}+$ channel to L-type $\mathrm{Ca} 2+$ channels via alpha-actinin2. Circ Res 2007;100:112-120. [PubMed: 17110593]

Maison S, Adams J, Liberman M. Olivocochlear innervation in the mouse: immunocytochemical maps, crossed versus uncrossed contributions, and transmitter colocalization. J Comp Neurol 2003;455:406-416. [PubMed: 12483691]

Maison S, Vetter D, Liberman M. A novel effect of cochlear efferents: in vivo response enhancement does not require alpha9 cholinergic receptors. J Neurophysiol 2007;97:3269-3278. [PubMed: 17344378]

Michna M, Knirsch M, Hoda J, Muenkner S, Langer P, Platzer J, Striessnig J, Engel J. Cav1.3 (alpha1D) $\mathrm{Ca} 2+$ currents in neonatal outer hair cells of mice. J Physiol 2003;553:747-758. [PubMed: 14514878]

Moser N, Mechawar N, Jones I, Gochberg-Sarver A, Orr-Urtreger A, Plomann M, Salas R, Molles B, Marubio L, Roth U, Maskos U, Winzer-Serhan U, Bourgeois JP, Le Sourd AM, De Biasi M, Schroder 
H, Lindstrom J, Maelicke A, Changeux JP, Wevers A. Evaluating the suitability of nicotinic acetylcholine receptor antibodies for standard immunodetection procedures. J Neurochem 2007;102:479-492. [PubMed: 17419810]

Nemzou NRM, Bulankina A, Khimich D, Giese A, Moser T. Synaptic organization in cochlear inner hair cells deficient for the CaV1.3 (alpha1D) subunit of L-type Ca2+ channels. Neuroscience 2006;141:1849-1860. [PubMed: 16828974]

Nenov A, Norris C, Bobbin R. Acetylcholine response in guinea pig outer hair cells. II. Activation of a small conductance $\mathrm{Ca}(2+)$-activated K+ channel. Hear Res 1996;101:149-172. [PubMed: 8951441]

Oliver D, Klöcker N, Schuck J, Baukrowitz T, Ruppersberg J, Fakler B. Gating of Ca2+-activated K+ channels controls fast inhibitory synaptic transmission at auditory outer hair cells. Neuron 2000;26:595-601. [PubMed: 10896156]

Rasmussen GL. An efferent cochlear bundle. Anat Rec 1942;82:441.

Russell IJ, Murugasu E. Medial efferent inhibition suppresses basilar membrane responses to near characteristic frequency tones of moderate to high intensities. J Acoust Soc Am 1997;102:1734 1738. [PubMed: 9301050]

Rüttiger L, Sausbier M, Zimmermann U, Winter H, Braig C, Engel J, Knirsch M, Arntz C, Langer P, Hirt B, Müller M, Köpschall I, Pfister M, Münkner S, Rohbock K, Pfaff I, Rüsch A, Ruth P, Knipper M. Deletion of the $\mathrm{Ca} 2+$-activated potassium $(\mathrm{BK})$ alpha-subunit but not the BKbeta1-subunit leads to progressive hearing loss. Proc Natl Acad Sci USA 2004;101:12922-12927. [PubMed: 15328414]

Shapira M, Zhai RG, Dresbach T, Bresler T, Torres VI, Gundelfinger ED, Ziv NE, Garner CC. Unitary assembly of presynaptic active zones from Piccolo-Bassoon transport vesicles. Neuron 2003;38:237252. [PubMed: 12718858]

Vetter DE, Katz E, Maison SF, Taranda J, Turcan S, Ballestero J, Liberman MC, Elgoyhen AB, Boulter $\mathrm{J}$. The $\alpha 10$ nicotinic acetylcholine receptor subunit is required for normal synaptic function and integrity of the olivocochlear system. Proc Natl Acad Sci U S A 2007;104:20594-20599. [PubMed: 18077337]

Vetter DE, Liberman MC, Mann J, Barhanin J, Boulter J, Brown MC, Saffiote-Kolman J, Heinemann $\mathrm{SF}$, Elgoyhen AB. Role of alpha9 nicotinic ACh receptor subunits in the development and function of cochlear efferent innervation. Neuron 1999;23:93-103. [PubMed: 10402196]

Walsh E, McGee J, McFadden S, Liberman M. Long-term effects of sectioning the olivocochlear bundle in neonatal cats. J Neurosci 1998;18:3859-3869. [PubMed: 9570815]

Whitlon D, Zhang X, Pecelunas K, Greiner M. A temporospatial map of adhesive molecules in the organ of Corti of the mouse cochlea. J Neurocytol 1999;28:955-968. [PubMed: 10900097]

Whitlon DS, Rutishauser US. NCAM in the organ of Corti of the developing mouse. J Neurocytol 1990;19:970-977. [PubMed: 2292721] 


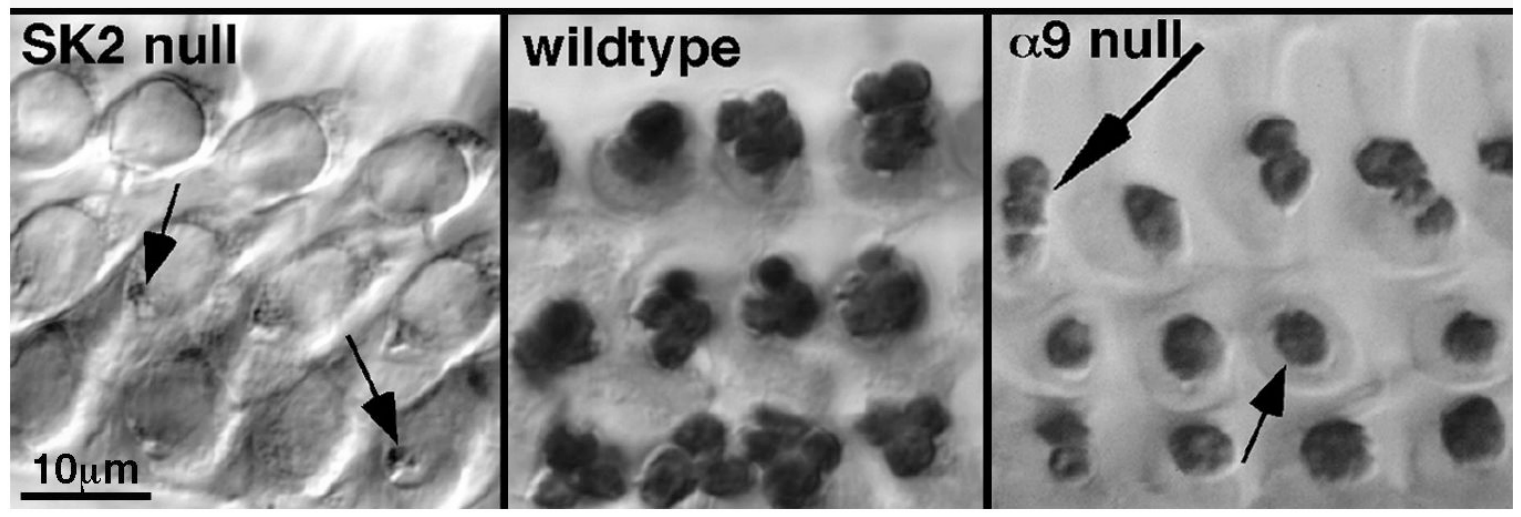

Fig. 1. Olivocochlear synaptic boutons degenerate in $\mathrm{SK} 2^{-/-}$mice Synaptophysin immunostaining reveals olivocochlear (efferent) synaptic terminals under outer hair cells. In wild types (left panel), outer hair cells are contacted by 2-5 synaptic boutons (arrows). In $\alpha 9^{-/-}$mice (right panel), olivocochlear terminals are most often less numerous (1-2 per outer hair cell) but larger (hypertrophied, small arrow), although occasionally hair cells are contacted by 2-3 boutons (large arrow). In SK2 ${ }^{-/-}$mice (middle panel), terminals (arrows) progressively degenerate. All images are from mid-cochlea regions of adults (8-12 weeks old). Scale bar applies to all panels. 


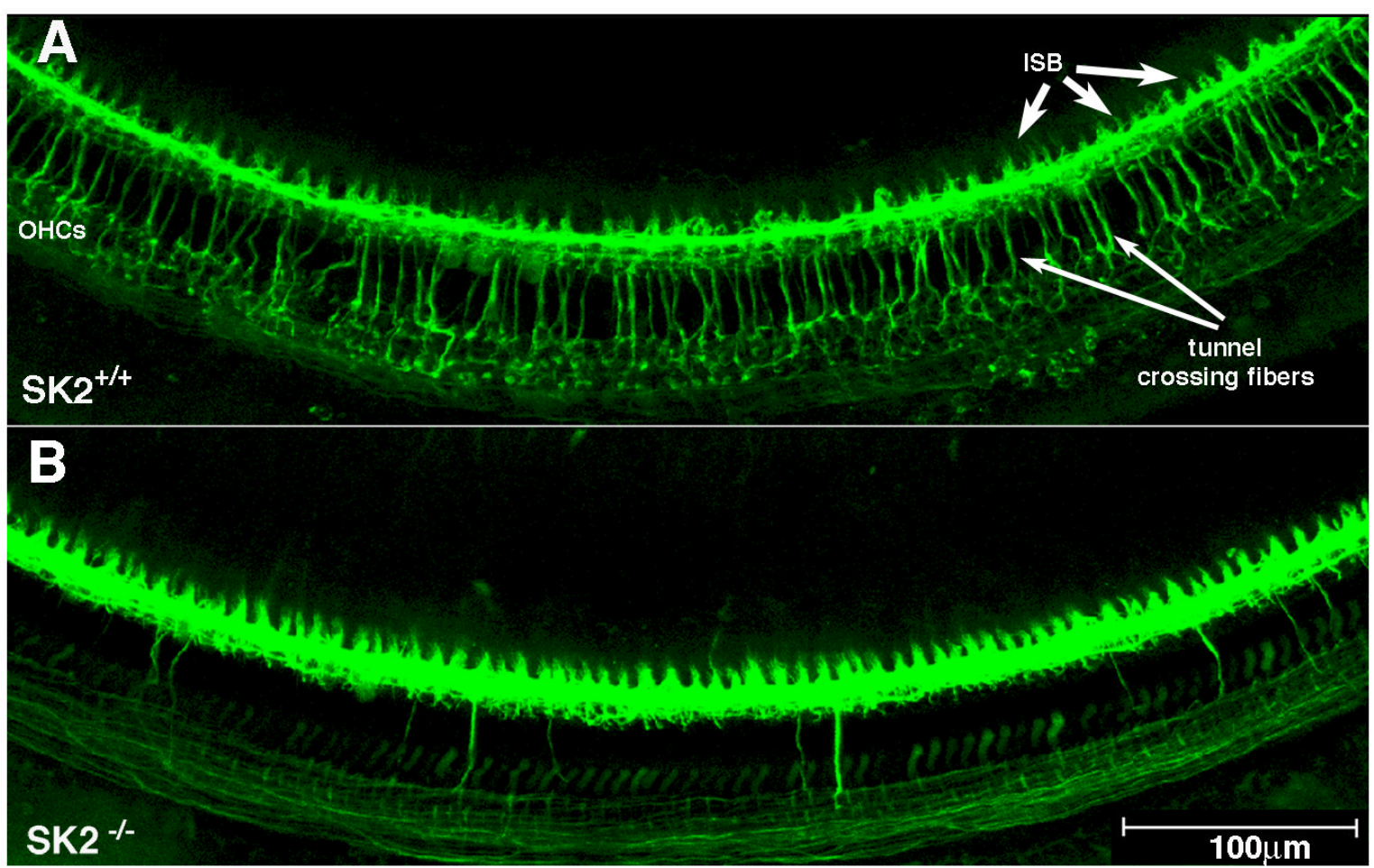

Fig. 2. Olivocochlear fibers degenerate in $\mathrm{SK}^{-/-}$mice

Immunostaining for neurotubules and synaptic vesicles (anti-TuJ and anti-synaptophysin; same color) reveals the efferent innervation in a wild type mouse (A) and the loss of efferent innervation in an SK2 ${ }^{-/-}$mouse (B). A: Wild type mice show numerous olivocochlear fibers crossing the tunnel of Corti to the outer hair cells (OHCs; long arrows). The inner spiral bundle (ISB, short arrows), which carries olivocochlear fibers to the inner hair cell area, is also labeled. B: In SK2 ${ }^{-/-}$mice, the number of tunnel crossing fibers and olivocochlear terminals is greatly reduced. Scale bar applies to both panels. 

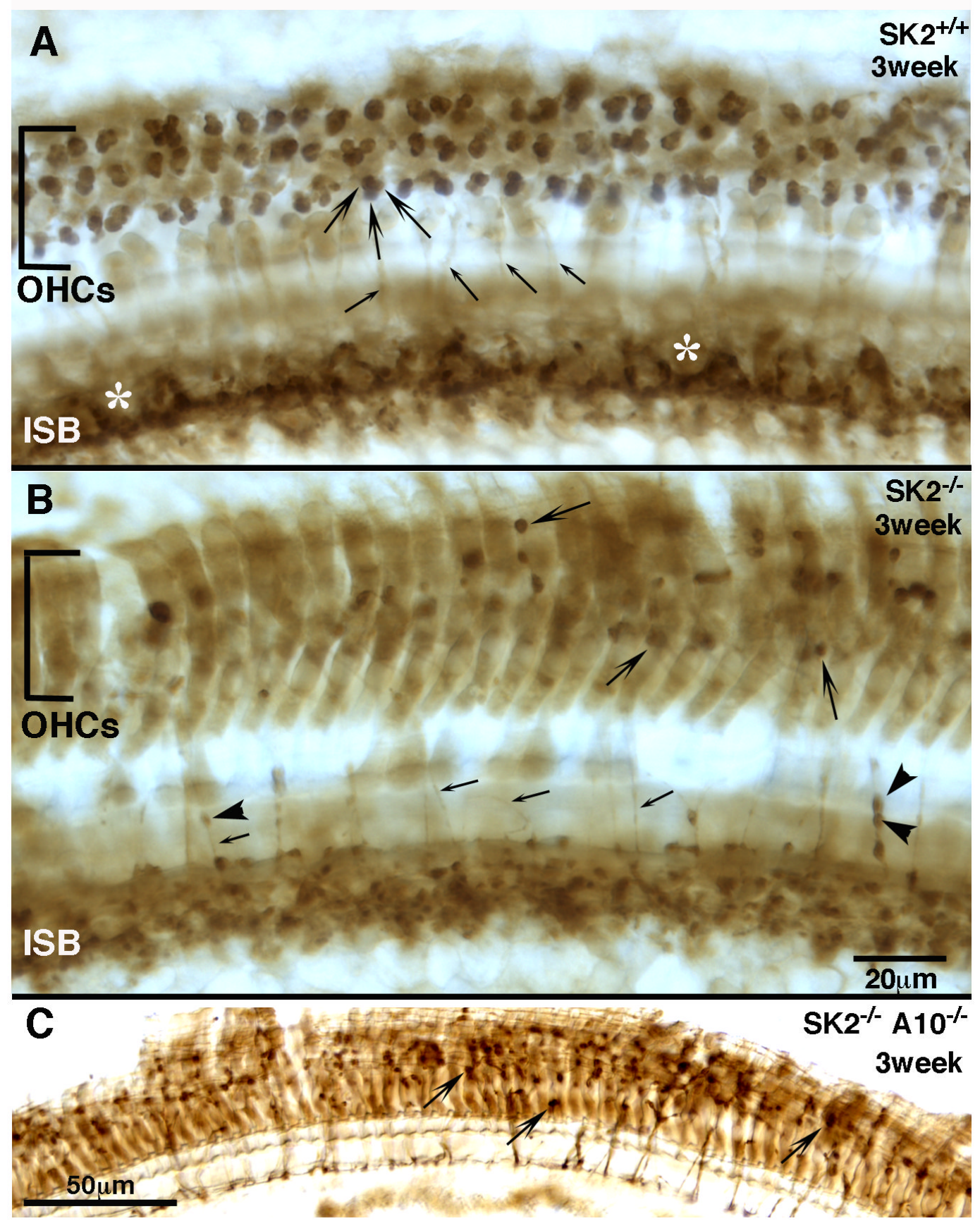

Fig. 3. Olivocochlear degeneration is incomplete at 3 weeks in both inner and outer hair cell areas Synaptophysin immunostaining shows the reduction of olivocochlear terminals in SK2 ${ }^{-/-}$and $\mathrm{SK}^{-/-} / \alpha 10^{-/-}$mice at 3 weeks of age. A: In wild types, there are $2-4$ OC terminals per OHC (large arrows), and the inner spiral bundle (ISB) is dense with terminal and en passant swellings surronding the inner hair cells (position marked by asterisks). Additionally, numerous tunnel crossing fibers (small arrows) are observed. B: In SK2 ${ }^{-/-}$mice, olivocochlear terminals in the $\mathrm{OHC}$ region are fewer and more varied in size (large arrows). The ISB is more disorganized, and no distinct cupping occurs around the inner hair cells. Fewer tunnel crossing fibers are present, and those that remain often times possess varicosities along their length (arrowheads). C: The double-null mice resemble the $\mathrm{SK} 2^{-/-}$mice, with scattered, smaller olivocochlear 
terminals in the $\mathrm{OHC}$ region (large arrows) and few tunnel crossing fibers Scale bar in B is for A-B. All images are from the middle of the cochlea. 


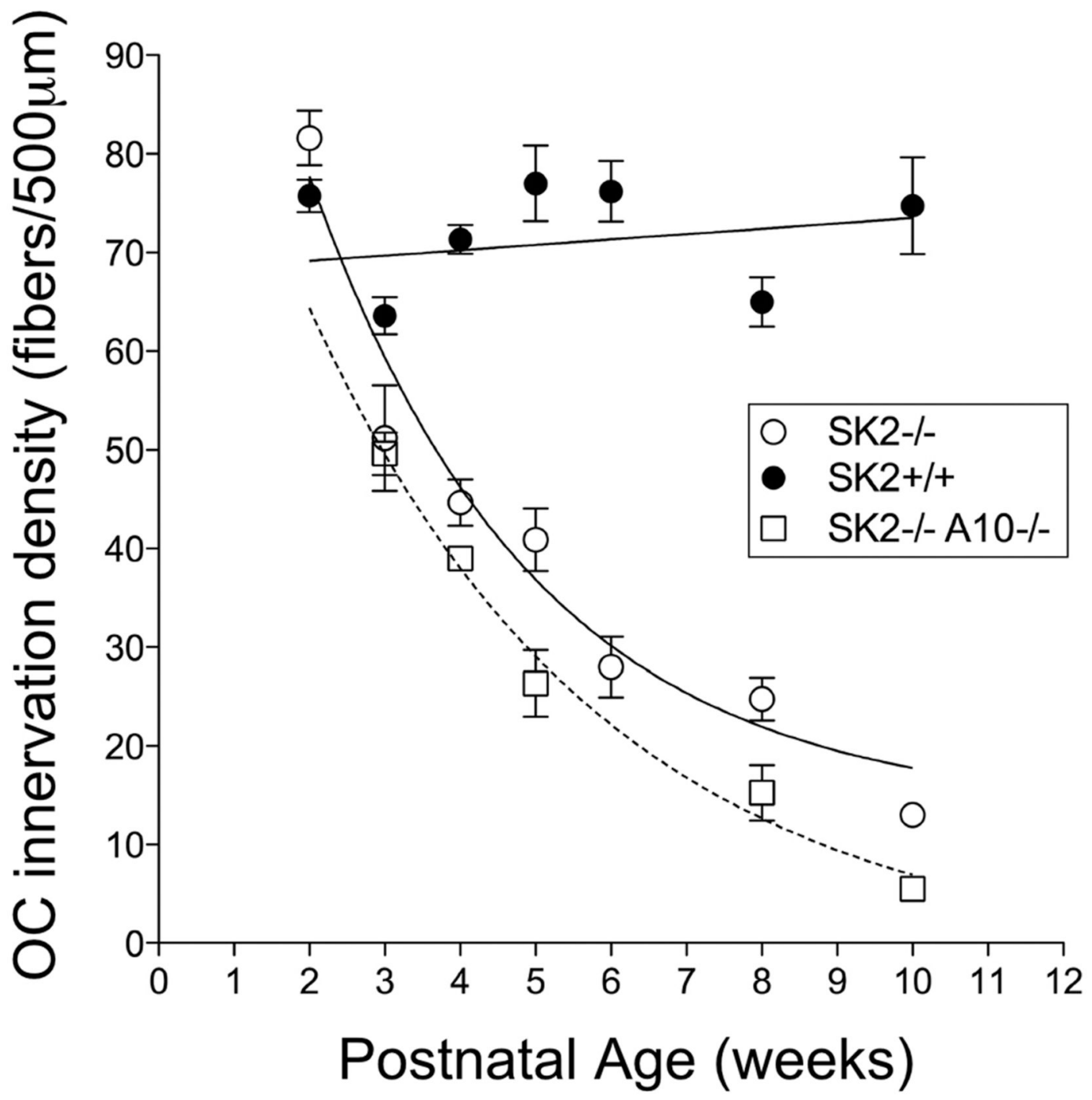

Fig. 4. Quantification of olivocochlear degeneration over postnatal time Counting olivocochlear tunnel-crossing fibers reveals a progressive degeneration in SK2 $2^{-/-}$ (open circles) and SK $2^{-/-} / \alpha 10^{-/-}$(open squares) compared to wild type (filled circle). SK2 $2^{-/-}$ mice begin with approximately the same number of fibers as wild type mice ( 2 weeks of age), but steadily decline in numbers over 10 weeks. The double SK2 $2^{-/} / \alpha 10^{-/-}$mice exhibit a similar degeneration profile, but the rate of degeneration is increased. Means and SEMs are shown. Data are from the middle of the cochlea in 4-7 cochleae of each genotype at each age. 

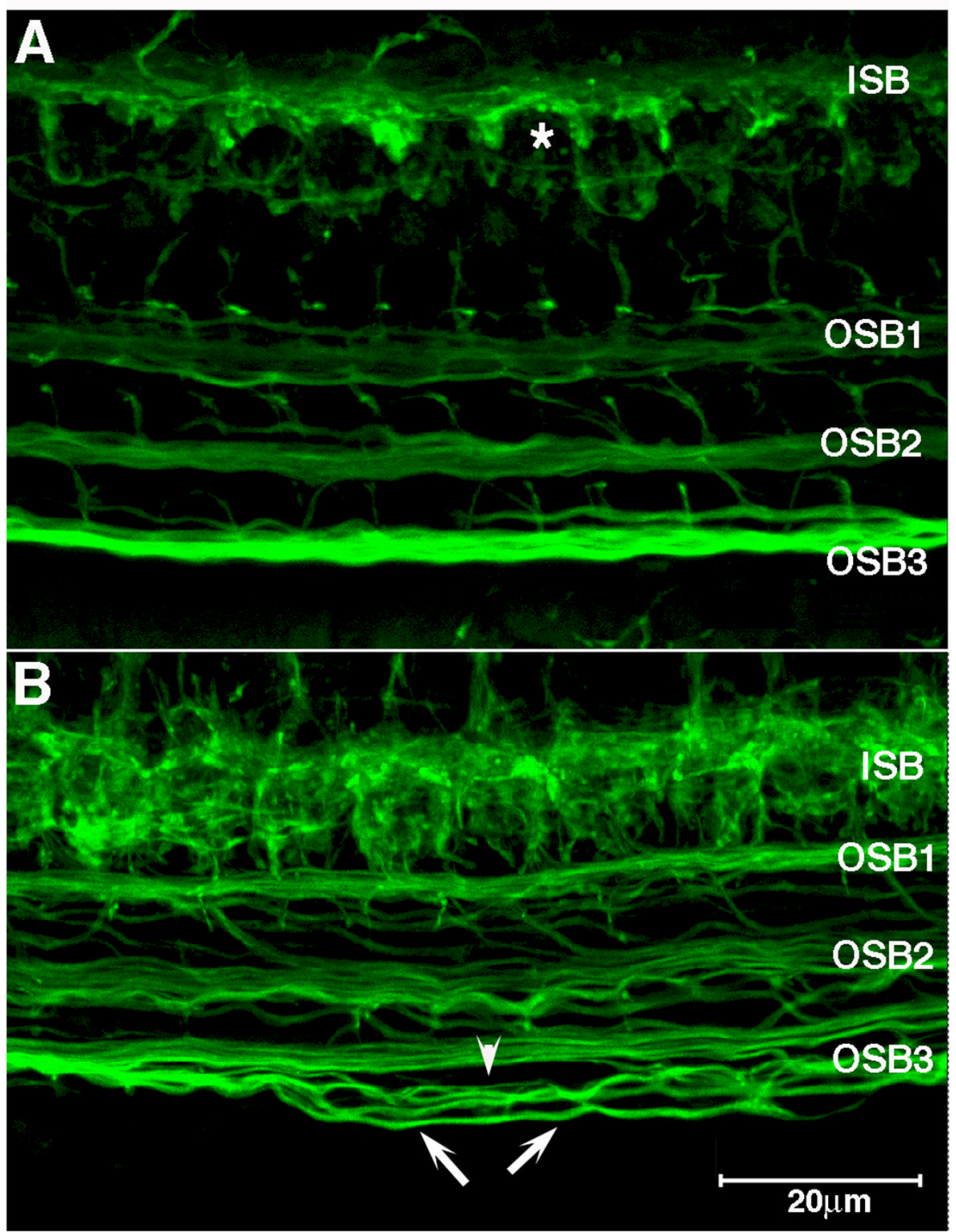

Fig. 5. Afferent fibers under outer hair cells and efferent fibers in the inner hair cell region are defasciculated in $\mathrm{SK}^{-/-}$mice

Immunostaining of afferent and efferent fibers with TuJ1 reveals alterations in fiber fasciculation. A: Afferent fibers under the outer hair cells, running as the outer spiral bundle (OSB) and efferent fibers in the inner spiral bundle (ISB), run as tight bundles in wild type mice. The inner spiral bundle (ISB) is compact and outlines the region occupied by unstained inner hair cells (asterisk identifies one such region). B: In the SK2 $2^{-/-}$mice, OSB fibers are defasciculated (arrowhead) from the main bundle, and run as individual fibers (arrows). The ISB is likewise disorganized, and IHC pockets are seldom observed. 


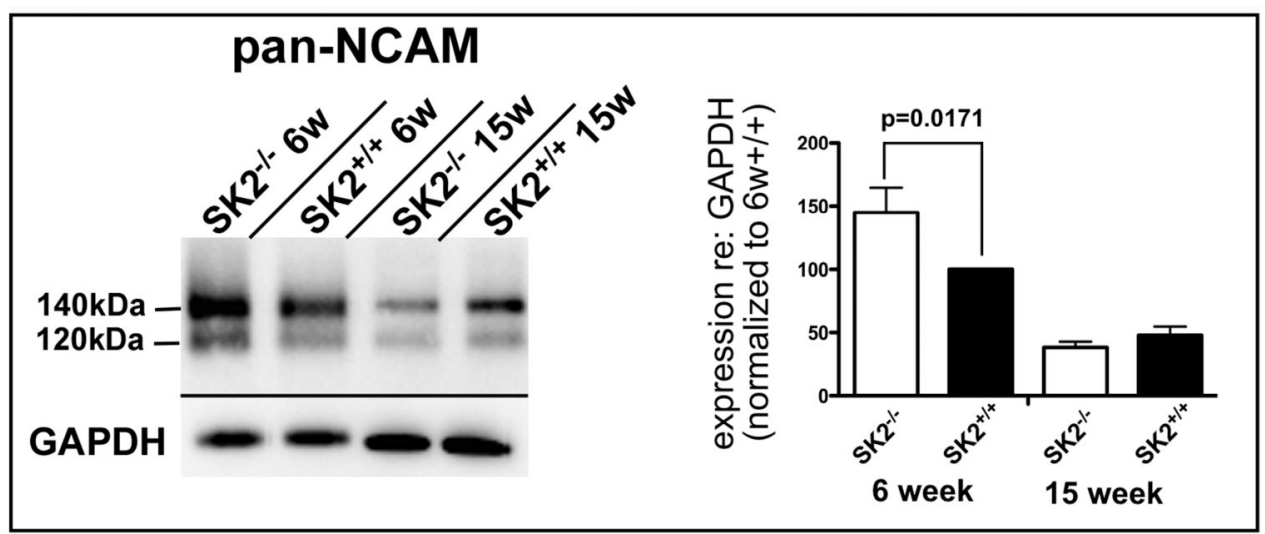

Fig. 6. Protein expression levels of cell adhesion molecules NCAM and N-cadherin are upregulated in $\mathrm{SK}^{-/-}$mice

A: Western blot analysis reveals that at 6 weeks of age, a time at which approximately $40 \%$ of OC fibers remain and are still actively degenerating, NCAM expression is significantly upregulated by approximately $50 \%$ over the level of the wild type age-matched control $(\mathrm{p}=0.0171)$. At 15 weeks, a time at which degenerative processes are complete, NCAM expression appears slightly lower that wild type age-matched samples, but no statistically significant difference was detected. Histogram is relevant for the 140kDa NCAM isoform (the major isoform expressed in the cochlear lysate). 


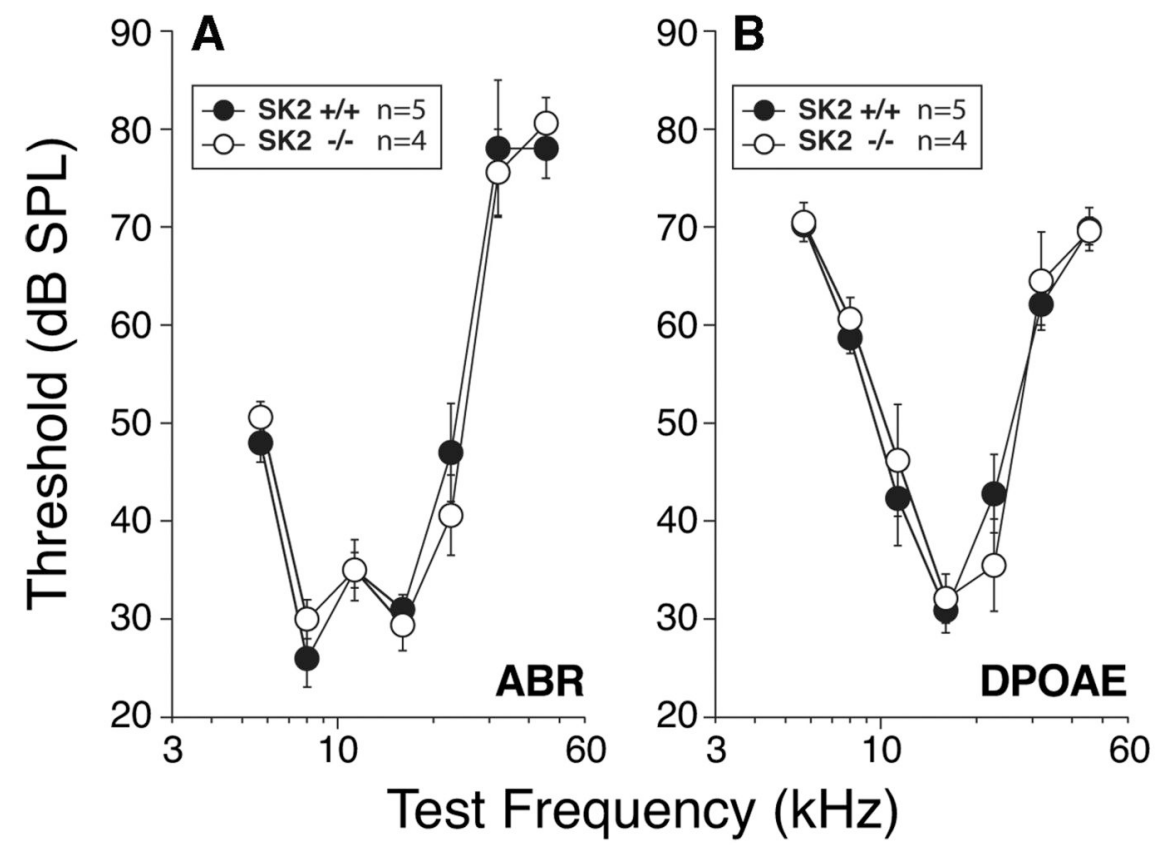

Fig. 7. Baseline cochlear sensitivity is unaffected in $\mathrm{SK}^{-/-}$mice

Mean thresholds $( \pm$ SEM) for auditory brainstem thresholds (A) and distortion product otoacoustic emissions (DPOAEs) (B) are shown for 8 wildtype vs. SK2 ${ }^{-/-}$ears at 8 weeks of age. No statistical differences are found between $\mathrm{SK} 2^{-/-}$and wild type mice. 

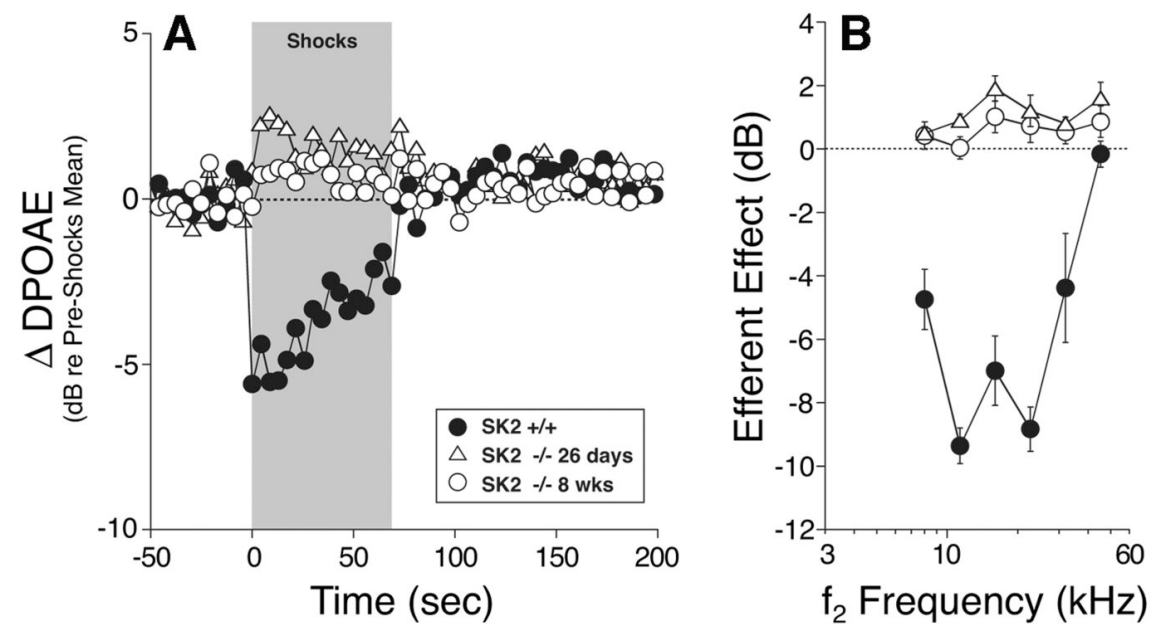

Fig. 8. Olivocochlear-mediated suppression of cochlear responses is absent in SK2/- mice A: The normal suppression of cochlear responses seen during shock trains to the olivocochlear bundle is absent in SK2 ${ }^{-/-}$ears, and is replaced by a small response enhancement. DPOAE amplitudes are normalized to the average pre-shock value. Test frequency was $16 \mathrm{KHz}$. B: Mean $\left( \pm\right.$ SEM) efferent effect in 7 wild type and 8 SK2 ${ }^{-/-}$ears, defined as the average change in the DPOAE amplitude (in $\mathrm{dB}$ ) for the first three measurements after shock-train onset. 


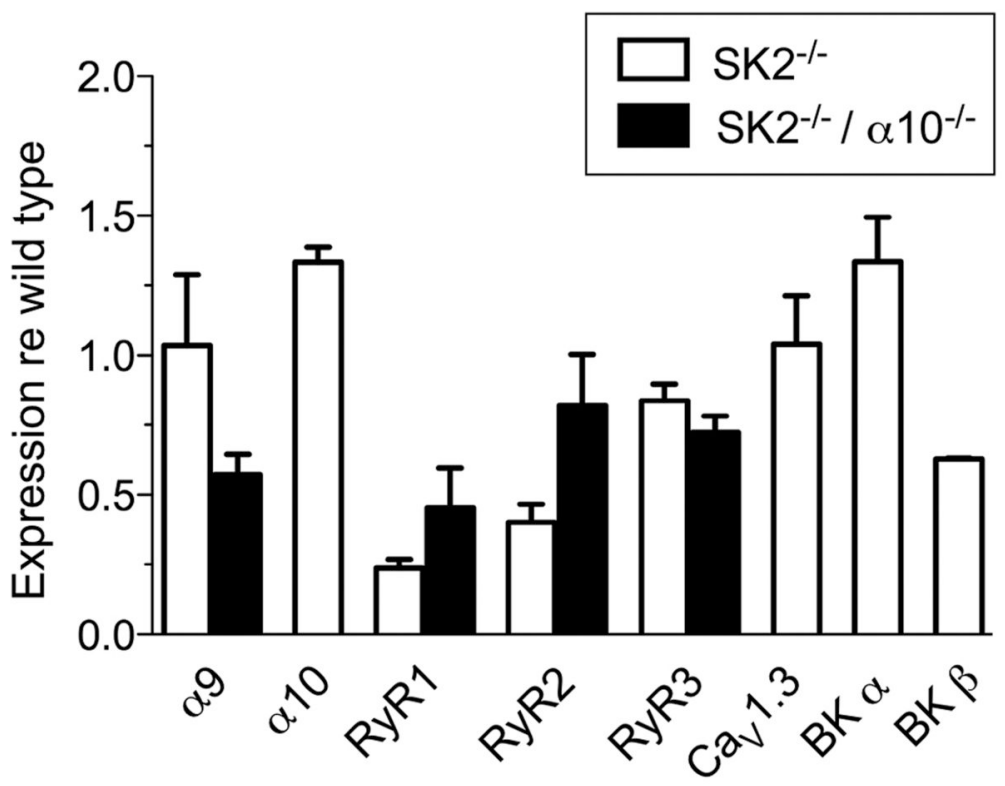

Fig. 9. Expression of other genes is altered by loss of SK2

Quantitative RT-PCR on cochleas from wild type, SK2 $2^{-/-}$, and SK $2^{-/-} / \alpha 10^{-/-}$ears showed that ryanodine receptors were down regulated in both null lines. The $\alpha 9 \mathrm{nAChR}$ gene was down regulated, but only when both SK2 and $\alpha 10 \mathrm{nAChR}$ were deleted. Whereas BK $\alpha$ was slightly up regulated following loss of the SK2 gene, BK $\beta$ was significantly down regulated. The beta subunit is known to confer calcium and voltage changes to the main, alpha, subunit, and thus this change may have significant but until now unrecognized physiological consequences. $\Delta \Delta \mathrm{Ct}$ analysis was carried out as described in Methods. Expression levels were averaged among all replicates between qPCR runs, and plotted with standard deviations. 


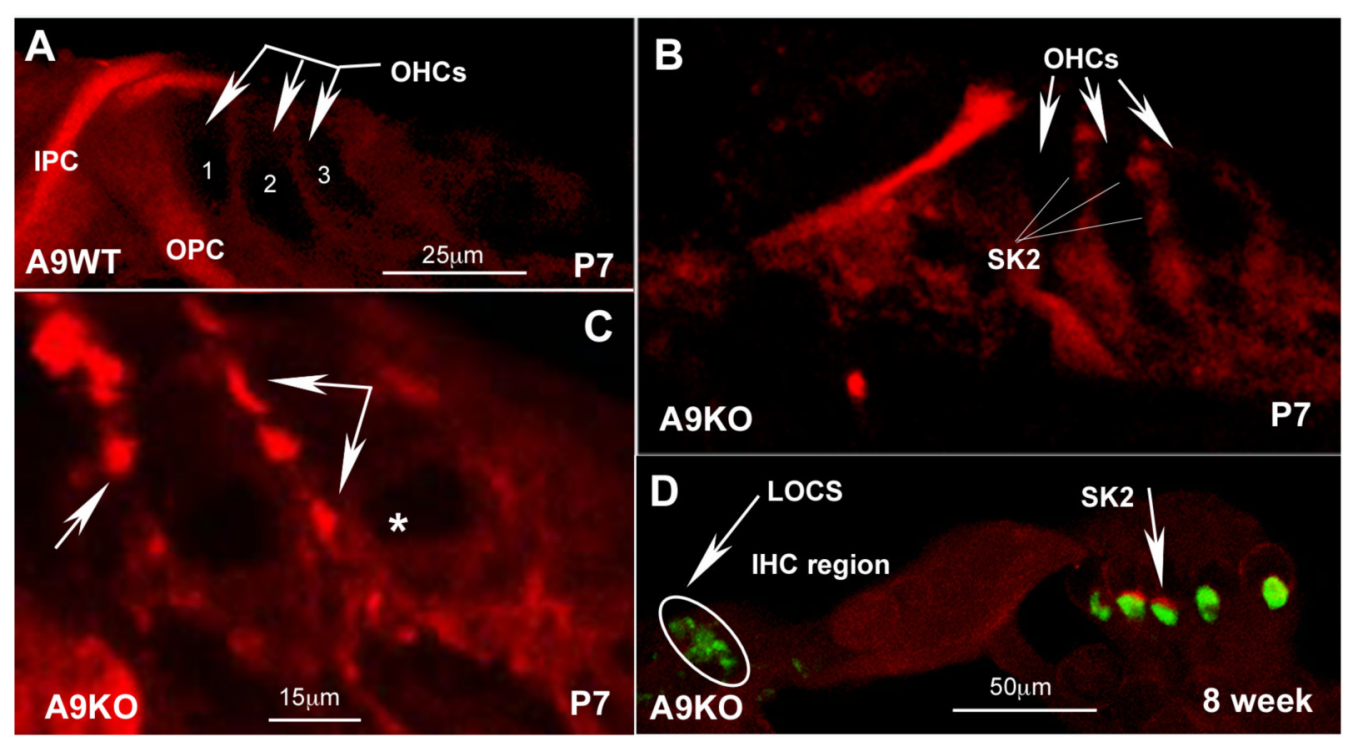

Fig. 10. SK2 expression during early synaptic refinement periods and in the adult cochlea in mice lacking the $\mathrm{nAChR} \alpha 9$ subunit

A: SK2 immunostaining of P7 wild type mice demonstrates no detectable expression in the $\mathrm{OHC}$ region. Inner and outer pillar cells (IPC, OPC) are immunopositive, but no distinct localization is apparent. B: In $\alpha 9^{-/-}$mice, distinct localization of SK2 along the lateral walls of OHCs can be observed at P7 as indicated by the line segments. Scale bar in A applies also to B. C: At higher magnification, the distinct localization of SK2 along the lateral walls of the $\mathrm{OHC}$ is more readily apparent. A few of the SK2 puncta are indicated by arrows. The nucleus of one OHC is indicated by an asterisk for purposes of orientation. D: In the mature $\alpha 9^{-/-}$ cochlea, SK2 puncta (red, one of which is indicated by an arrow) are lost from the lateral walls, and have collapsed to take up a position apposed to the incoming OC terminals, stained by synaptophysin antibodies (green). The lateral olivocochlear system (LOCS) is indicated in the inner hair cell region for orientation purposes. 